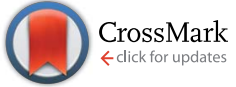

Cite this: RSC Adv., 2017, 7, 7531

Received 26th October 2016 Accepted 9th January 2017

DOI: $10.1039 / c 6 r a 25841 g$

www.rsc.org/advances

\section{A review on the application of inorganic nanoparticles in chemical surface coatings on metallic substrates}

\author{
Cong-cong Jiang, ${ }^{\text {abc }}$ Yan-ke Cao, ${ }^{d}$ Gui-yong Xiao, ${ }^{\text {abc }}$ Rui-fu Zhu ${ }^{\text {abc }}$ \\ and Yu-peng $\mathrm{Lu}^{\star \mathrm{abc}}$
}

Chemical surface coatings not only provide a powerful barrier between metallic substrates and their surroundings but also impart desired surface performances to an underlying substrate. Chemical surface coatings not only provide a powerful barrier between metallic substrates and their surroundings but also impart desired surface performances to an underlying substrate. Recently, the increasing public concern with industrial finishing systems has driven many investigations on the functional modification, such as the use of special chemical additives in the treatment bath, pre- and post-processing, of chemical surface coatings. However, these methods are being phased out due to their possible high-cost or harmful effects. Controlled addition of inorganic nanoparticles, without poison and contamination, to the treatment bath has become a good alternative due to the on-demand properties, including enhanced corrosion resistance and mechanical and functional properties, triggered by nanoparticles. This study focuses on the applications of inorganic nanoparticles in various chemical surface coatings such as electroless plating, electroplating, silane, and chemical conversion coatings. The discussed inorganic nanoparticles include $\mathrm{TiO}_{2}, \mathrm{SiO}_{2}, \mathrm{Al}_{2} \mathrm{O}_{3}, \mathrm{ZrO}_{2}, \mathrm{SiC}, \mathrm{ZnO}, \mathrm{CeO}_{2}, \mathrm{MoS}_{2}$, and diamond and graphite nanoparticles. This review is also concerned with the dispersion methods of inorganic nanoparticles as well as the formation mechanism of nanocomposite coatings.

\section{Introduction}

Metallic materials are of great importance in the fields of national manufacturing and construction due to their combined desirable qualities, such as high-strength, workability, low-cost, and ability to be recycled, ${ }^{\mathbf{1 , 2}}$ and are thereby suggested for a variety of applications such as in household equipment, automobile and aerospace components. ${ }^{3,4}$ However, their susceptibility to corrosion has become a leading cause of either failure or unfitness for application in engineering components, ${ }^{2}$ thus both causing tremendous economic loss and posing a serious threat to national resources. Therefore, it is significantly required to change the surface properties of metallic devices to prevent contact with severe environments and therefore protect the underlying metals from corrosive damage under the condition of reserving its original properties. The most cost-effective and simple technique involves a proper

\footnotetext{
${ }^{a}$ Key Laboratory for Liquid-Solid Structural Evolution and Processing of Materials, Ministry of Education, Shandong University, Jinan, 250061, China. E-mail: Lu-biosdu@sdu.edu.cn; Fax: +86 531 88395966; Tel: +86 53188395966

${ }^{b}$ School of Materials Science and Engineering, Shandong University, Ji'nan, 250061, China

'Suzhou Institute, Shandong University, Suzhou, 215123, China

'Jinan No. 2 Machine-Tool Group Co., Ltd, Ji'nan, 250022, China
}

coating system on the surface of metallic substrates. ${ }^{2,3,5-7}$ Numerous techniques, such as electrodeposition, ${ }^{\mathbf{8 , 9}}$ electroless plating, ${ }^{10,11}$ plasma thermal spraying, ${ }^{12}$ chemical conversion coating ${ }^{\mathbf{1 3}, 14}$ gas phase deposition, ${ }^{\mathbf{1 5 , 1 6}}$ (physical vapour deposition and chemical vapour deposition), ion implantation, ${ }^{17}$ laser surface alloying, ${ }^{18}$ and organic coating ${ }^{\mathbf{1 9 , 2 0}}{ }^{\mathbf{1 0}}$ have been exploited to confer protective surface coatings to an underlying substrate. These coatings supply exciting properties to the underlying substrates via a variety of mechanisms, including the formation of an effective physical barrier to the penetration of corrodents, as an excellent base for both electrophoretic painting and powder coating, reducing wear on the machine elements and moving parts, and aid in the cold forming of steel. Moreover, the abovementioned coatings also offer the advantages of improved solderability, electrical conductivity, and decorative appearance. ${ }^{3,5-7,21-23}$ Therefore, these treatments greatly contribute to the manufacturing as well as play a pivotal role in surface machining systems. Traditionally, many modifications, such as pretreatments, post-treatments, and altering the compositions of the treatment bath, for surface coatings on the metallic substrates have been put forth over the decades. ${ }^{5,7,24}$ However, these methods are being phased out due to their possible highcost or harmful effects. Controlled addition of inorganic nanoparticles, without poison and contamination, to the treatment bath has become a good alternative. Research on the production 
of nanocomposite coatings by the co-deposition of nanoparticles with the original coating has been widely investigated by numerous investigators in the past two decades mainly due to the fact that nanocomposite coatings can deliver various on-demand properties, including enhanced corrosion resistance, and mechanical and functional properties, to a treated surface. ${ }^{5,6,25,26}$ Thus, the application of inorganic nanoparticles in surface coating is able to open up exciting opportunities for the anticorrosive and multifunctional modification of protective surface coatings over many metals. This study summarizes the application of inorganic nanoparticles in various chemical surface coatings such as electroless plating, electroplating, silane and chemical conversion coatings. In view of the challenge of dispersing nanoparticles, this review is also concerned with the dispersion methods of inorganic nanoparticles as well as the formation mechanism of nanocomposite coatings.

\section{Use of inorganic nanoparticles in chemical surface coatings}

The earliest industrial application and basic role of a surface coating were only corrosion protection for metallic substrates due to the effective physical barrier provided by a surface coating. ${ }^{7,27}$ Besides its efficiency against corrosion, another great concern about the use of a surface coating is its mechanical properties such as hardness, wear, and lubricity. When used in practice, a surface coating on a metallic substrate needs to be capable of resisting mechanical damages caused by impact, wear, and scratches. ${ }^{22}$ Note that researchers have found that the incorporation of nanoparticles into a coating has become an alternative way to further improve the corrosion resistance and mechanical properties of the existing surface coating to keep up with the rapidly changing needs of certain special applications. ${ }^{5,6}$ In fact, the improvement in surface properties originates from the microstructure of a nanocomposite coating incorporated with well-dispersed nanoparticles; therefore, the effects of nanoparticles on various surface treatments, including electroless plating, electroplating, silane and chemical conversion coating, have been described in detail in the following sections.

\subsection{Electroless plating}

Electroless plating is an autocatalytic process in which the reduction of metallic ions and formation of a coating can be carried out via the oxidation of reducing agents in the treatment bath. ${ }^{6,28}$ Electroless plating has recently gained wide acceptance due to its excellent corrosion and wear resistance. ${ }^{6,22}$ Many metals, such as nickel, ${ }^{29}$ copper, ${ }^{30}$ gold, ${ }^{31}$ silver ${ }^{32}$ palladium, ${ }^{33}$ and cobalt, ${ }^{34}$ have been widely deposited as electroless coatings. These coatings have proven useful both in the computer and electronics industries for enhanced corrosion and wear resistance, solderability, as well as in a variety of space applications for improved electrical conductivity and optical reflectance. ${ }^{6,22}$ The industrial use of electroless $\mathrm{Ni}$, especially the Ni-P alloy, ${ }^{35,36}$ has steadily grown during the last decade because of its unique properties such as good weldability, electrical conductivity, and uniform coating thickness. Although electroless Ni-P can serve many purposes, the quest for further improved mechanical
Table 1 Inorganic nanoparticles applied in electroless $\mathrm{Ni}-\mathrm{P}$

\begin{tabular}{|c|c|c|c|}
\hline Nanoparticle & Average size & Addition content & Substrate \\
\hline \multirow[t]{3}{*}{$\begin{array}{l}\mathrm{SiO}_{2} \\
\text { (ref. 39-43) }\end{array}$} & $15-20 \mathrm{~nm}$ & $5-15 \mathrm{~g} \mathrm{~L}^{-1}$ & $\begin{array}{l}\text { Al 7075-T6/AZ91 } \\
\text { Mg alloy }\end{array}$ \\
\hline & $10-20 \mathrm{~nm}$ & $0-2 \mathrm{~g} \mathrm{~L}^{-1}$ & $\mathrm{Cu} / \mathrm{AISI}-1045$ \\
\hline & $20 \mathrm{~nm}$ & $7 \mathrm{~g} \mathrm{~L}^{-1}$ & API-5L X65 steel \\
\hline $\mathrm{TiO}_{2}$ (ref. 10) & $200-300 \mathrm{~nm}$ & $0.5-2 \mathrm{~g} \mathrm{~L}^{-1}$ & Carbon steel \\
\hline $\mathrm{TiO}_{2} \mathrm{sol}^{44}$ & $15 \mathrm{~nm}$ & $120 \mathrm{~mL} \mathrm{~L}^{-1}$ & AZ31 Mg alloy \\
\hline $\mathrm{Al}_{2} \mathrm{O}_{3}$ (ref. 45) & $80-90 \mathrm{~nm}$ & $5-20 \mathrm{~g} \mathrm{~L}^{-1}$ & Mild steel \\
\hline $\mathrm{ZrO}_{2}$ (ref. 46) & $100 \mathrm{~nm}$ & $3 \mathrm{~g} \mathrm{~L}^{-1}$ & AISI 304 \\
\hline $\mathrm{SiC}^{47}$ & $50 \mathrm{~nm}$ & $2-8 \mathrm{~g} \mathrm{~L}^{-1}$ & Mild steel \\
\hline $\mathrm{CeO}_{2}$ (ref. 48) & $20 \mathrm{~nm}$ & $20 \mathrm{~g} \mathrm{~L}^{-1}$ & Low carbon steel \\
\hline Diamond $^{28}$ & $4 \mathrm{~nm}$ & $0-200 \mathrm{mg} \mathrm{L}^{-1}$ & St-37 steel \\
\hline Graphite $^{49}$ & $15-40 \mathrm{~nm}$ & $1-20 \mathrm{~g} \mathrm{~L}^{-1}$ & Al-Mg alloy AA5083 \\
\hline $\mathrm{MoS}_{2}$ (ref. 50) & $80-100 \mathrm{~nm}$ & $1-4 \mathrm{~g} \mathrm{~L}^{-1}$ & Medium carbon steel \\
\hline
\end{tabular}
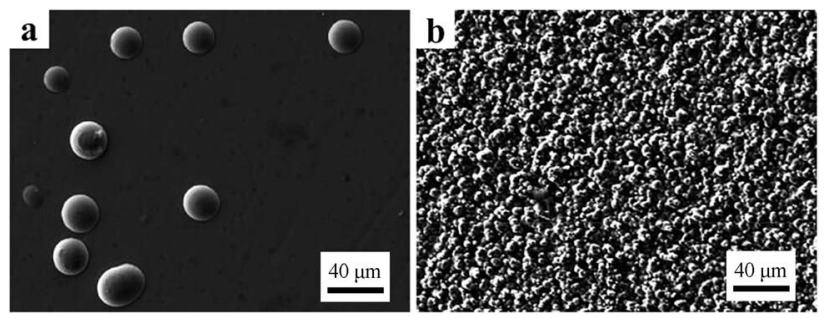

Fig. 1 SEM images of (a) electroless Ni-P and (b) Ni-P-SiC coatings on mild steel. (Reproduced from ref. 47, Copyright 2013, with permission from Elsevier Ltd.)

properties, such as higher hardness, lubricity, and anti-wear properties, has led to the incorporation of many inorganic nanoparticles into the Ni-P coating. ${ }^{6,28}$ These inorganic nanoparticles can be either hard or lubricant materials. Hard materials, such as $\mathrm{Al}_{2} \mathrm{O}_{3}, \mathrm{TiO}_{2}, \mathrm{CeO}_{2}$, and diamond, enhance the wear resistance since they can increase the hardness of the Ni-P coating. Lubricant materials, such as graphite and $\mathrm{MoS}_{2}$, have been used to decrease the friction coefficient of the electroless Ni-P and thus improve its wear resistance. The choice of nanoparticles depends on the specific property that is desired. ${ }^{35,37,38}$ The general categories of inorganic nanoparticles applied to electroless $\mathrm{Ni}-\mathrm{P}$ are summarized in Table 1.

The microstructure of a nanocomposite coating is deeply affected by the incorporation of nanoparticles into the coating. Many studies have proven the beneficial effect of nanoparticles in refining the crystal size, and then achieving a more compact coating. For instance, the presence of nano-SiC particles results in more and smaller spherical nodules in the electroless $\mathrm{Ni}-\mathrm{P}-$ SiC composite coating (Fig. 1). This may be interpreted as the nano-SiC particles provide more nucleation sites for $\mathrm{Ni}-\mathrm{P}$ deposition or limit the lateral growth of the Ni-P coating. ${ }^{47}$ Moreover, many studies have also revealed that this nanocomposite coating obtained by the controlled addition of nanoparticles into the treatment bath possesses less porosity than that of the conventional coatings, resulting in enhanced corrosion resistance. ${ }^{28,39,41,42,45,51}$ 
Table 2 Inorganic nanoparticles used in the electroplating of $\mathrm{Ni}$

\begin{tabular}{|c|c|c|c|c|}
\hline Nanoparticle & Average size & Addition content & Plating & Substrate \\
\hline $\mathrm{SiC}^{58}$ & $50 \mathrm{~nm}$ & $0-20 \mathrm{~g} \mathrm{~L}^{-1}$ & $\mathrm{Ni}$ & $\mathrm{Cu}$ \\
\hline \multirow[t]{2}{*}{$\mathrm{Al}_{2} \mathrm{O}_{3}$ (ref. 9, 52 and 61) } & $80 \mathrm{~nm}$ & $5-30 \mathrm{~g} \mathrm{~L}^{-1}$ & $\mathrm{Ni}$ & Low carbon steel \\
\hline & $100 \mathrm{~nm}$ & $0-10 \mathrm{~g} \mathrm{~L}^{-1}$ & $\mathrm{Ni}$ & Mild steel \\
\hline $\mathrm{Al}_{2} \mathrm{O}_{3}$ (ref. 62) & $250 \mathrm{~nm}$ & $50 \mathrm{~g} \mathrm{~L}^{-1}$ & $\mathrm{Ni}-\mathrm{Co}$ & Mild steel \\
\hline \multirow[t]{2}{*}{$\mathrm{ZrO}_{2}$ (ref. 25, 57 and 63) } & $20-60 \mathrm{~nm}$ & $5-10 \mathrm{~g} \mathrm{~L}^{-1}$ & $\mathrm{Ni}$ & $\mathrm{Cu}$ \\
\hline & $50 \mathrm{~nm}$ & $5-30 \mathrm{~g} \mathrm{~L}^{-1}$ & $\mathrm{Ni}-\mathrm{W}$ & Steel \\
\hline $\mathrm{CeO}_{2}$ (ref. 53, 59 and 64) & $30-40 \mathrm{~nm}$ & $30-40 \mathrm{~g} \mathrm{~L}^{-1}$ & $\mathrm{Ni}$ & Stainless steel \\
\hline \multirow[t]{2}{*}{$\mathrm{TiO}_{2}$ (ref. 65 and 66) } & $30 \mathrm{~nm}$ & $0-15 \mathrm{~g} \mathrm{~L}^{-1}$ & $\mathrm{Ni}$ & Steel \\
\hline & $<40 \mathrm{~nm}$ & $1,50,99 \mathrm{~g} \mathrm{~L}^{-1}$ & $\mathrm{Ni}-\mathrm{P}$ & Polycrystalline copper \\
\hline $\mathrm{TiO}_{2}$ sol $^{56,67-69}$ & $25 \mathrm{~nm}$ & $0-50 \mathrm{~mL} \mathrm{~L}^{-1}$ & $\mathrm{Ni}$ & $\mathrm{Cu} /$ carbon steel \\
\hline
\end{tabular}

\subsection{Electroplating}

Electroplating can produce a single metal and/or alloy as a coating on metallic substrates by use of the electrolytic principle with the purpose of improving the wear resistance, corrosion resistance, conductivity, and reflective and aesthetic properties. ${ }^{8,9,52}$ Electroplating has been shown to be useful in a number of applications, including the automotive, aerospace, and marine industries. ${ }^{5,53}$ Since Fink and Prince first reported the co-deposition of $\mathrm{Cu}$ and graphite for the self-lubricating surfaces in car engines, ${ }^{27}$ nanocomposite electroplated coatings obtained via the co-deposition of nanoparticles with metals have received significant attention owing to their enhanced mechanical properties, corrosion resistance, as well as the unique magnetic, catalytic, and optical properties compared to those of the traditional electroplating..$^{5,25,54}$ Among these, electroplated $\mathrm{Ni}$ and $\mathrm{Ni}$ alloy containing inorganic nanoparticles can be commonly seen due to the fact that there have been many reports on these in recent years. ${ }^{9,25,53,55-57}$ The most widely used nanoparticles in the electroplating of $\mathrm{Ni}$ are illustrated in Table 2. Typically pyramid-like Ni nodules are formed on the surface of the electroplated Ni, as shown in Fig. 2a. Some large protrusions of $\sim 1 \mu \mathrm{m}$ could be clearly seen in the inset of Fig. $2 \mathrm{a}$ and the surface is relatively rough and uneven. However, electroplated $\mathrm{Ni}^{-\mathrm{TiO}_{2}}$ is much smoother, with relatively homogeneous Ni nodules of $\sim 400 \mathrm{~nm}$ in size on its surface (Fig. $2 \mathrm{~b}$ ) and large clusters or protrusions almost disappear. ${ }^{56}$ Moreover, nano-SiC particles were embedded in the nickel matrix and filled in the crevices, gaps, and micron holes, which improved the corrosion resistance of electroplating. ${ }^{58}$ In addition, Xue

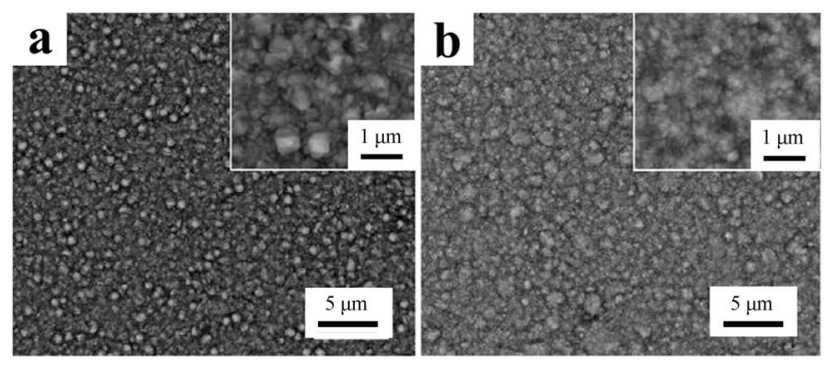

Fig. 2 Surface morphologies of (a) electroplated $\mathrm{Ni}$ and (b) $\mathrm{Ni}-\mathrm{TiO}_{2}$ on carbon steel. (Reproduced from ref. 56, Copyright 2010, with permission from Elsevier Ltd.) et $a .^{59}$ observed an improvement in the hardness and wear resistance of electroplated $\mathrm{Ni}$ by the addition of nano-SiC particles, which is attributed to the grain-fining and dispersive strengthening effect. Consistent results were obtained by García-Lecina et al. ${ }^{60}$ on an $\mathrm{Ni}-\mathrm{Al}_{2} \mathrm{O}_{3}$ composite coating where they proposed that the presence of fine, well-dispersed nano$\mathrm{Al}_{2} \mathrm{O}_{3}$ particles in the Ni matrix would act as strong obstacles for the dislocation movement.

\subsection{Organic silane coatings}

Organic silane coatings can act as environmentally friendly coatings on the underlying metals for improving the corrosion and wear resistance, decoration, and surface pretreatment before painting. ${ }^{20,70}$ When a metal is dipped into a silane bath for a few seconds, silanols ( $\mathrm{SiOH})$ in the bath spontaneously adsorb on the metal surface via hydrogen bonds. Upon drying, two key condensation reactions occur at the bath-metal interface. $\mathrm{SiOH}$ groups and metal hydroxyls $(\mathrm{MeOH})$ from the metal surface form covalent metallo-siloxane bonds (MeOSi) according to the following reaction:

$$
\mathrm{SiOH}_{\text {(bath) }}+\mathrm{MeOH}_{\text {(metal surface) }}=\mathrm{MeOSi}_{\text {(interface) }}+\mathrm{H}_{2} \mathrm{O}
$$

The excess $\mathrm{SiOH}$ groups adsorbed on the metal can also condense among themselves to form a siloxane (SiOSi) coating.

$$
\mathrm{SiOH}_{(\text {bath })}+\mathrm{SiOH}_{(\text {bath })}=\mathrm{SiOSi}_{(\text {silane coating) }}+\mathrm{H}_{2} \mathrm{O}
$$

The as-formed MeOSi and SiOSi covalent bonds are assumed to be responsible for the excellent bonding of the silane coatings to the metal substrates. ${ }^{70}$

However, the corrosion resistance of the conventional silane coating is far from satisfactory due to both its limited thickness (typical hundreds of nanometers) and low coverage on the underlying substrate. ${ }^{71,72}$ Nowadays, many efforts are being made to further improve the performance of silane coatings. Inorganic nanoparticles, such as $\mathrm{SiO}_{2}, \mathrm{TiO}_{2}$, and $\mathrm{CeO}_{2}$, as shown in Table 3, have been added to the silane bath to produce nanocomposite coatings. For instance, the nano- $\mathrm{TiO}_{2}$ particles incorporated silane coating presents a better performance for corrosion protection due to the formation of a thicker coating and enhanced barrier properties. ${ }^{73}$ Suegama $^{74}$ revealed that nano- $\mathrm{SiO}_{2}$ particles not only promote an increase in the 
Table 3 Inorganic nanoparticles used in organic silane coatings

\begin{tabular}{lllll}
\hline Nanoparticle & Size & Addition content & Silane & Substrate \\
\hline $\mathrm{SiO}_{2}$ (ref. 26, 70, 72 and 74) & $20 \pm 5 \mathrm{~nm}$ & $0-150 \mu \mathrm{g} \mathrm{L}^{-1}$ & Dodecyltrimethoxysilane & Al \\
& $10 \mathrm{~nm}$ & $300 \mathrm{ppm}$ & Bis-[trimethoxysilylpropyl]amine silane & Carbon steel \\
$\mathrm{CeO}_{2}$ (ref. 20) & $10-20 \mathrm{~nm}$ & $250 \mathrm{ppm}$ & Bis-[triethoxysilylpropyl]tetrasulfide silane & Galvanized steel \\
$\mathrm{CeO}_{2} \cdot \mathrm{ZrO}_{2}$ (ref. 75) & $30-40 \mathrm{~nm}$ & $250 \mathrm{ppm}$ & Bis-1,2-[triethoxysilylpropyl]tetrasulfide silane & Galvanized steel \\
$\mathrm{TiO}_{2}$ (ref. 71 and 73) & $50 \mathrm{~nm}$ & $0-1 \mathrm{~g} \mathrm{~L}^{-1}$ & Bis-[triethoxysilylpropyl]-tetrasulfide silane & Stainless steel \\
& $20 \pm 5 \mathrm{~nm}$ & $0-200 \mathrm{mg} \mathrm{L}^{-1}$ & Dodecyltrimethoxysilane &
\end{tabular}

hardness $(1.70 \pm 0.11 \mathrm{GPa}$ to $2.21 \pm 0.05 \mathrm{GPa})$ of a bis[trimethoxysilylpropyl]amine coating but also provide a better tribological behaviour. Apart from the enhanced corrosion resistance and mechanical properties, nanoparticles can also provide other functional properties to the silane coatings. On one hand, the photocathode protection of metals under ultraviolet irradiation via a silane coating filled with nano- $\mathrm{TiO}_{2}$ has been realized. For example, Liu et $a .^{71}$ studied a novel silane$\mathrm{TiO}_{2}$ bifunctional hybrid coating on stainless steel. In their study, nano- $\mathrm{TiO}_{2}$ particles not only facilitated the deposition of silane, but also enhanced the photocathode protection to the substrate under ultraviolet irradiation. This hybrid coating combined the photocatalysis of $\mathrm{TiO}_{2}$ with the protectiveness of the silane coating, which displayed the wider practical prospect of this surface treatment. On the other hand, the silane coating with nano-SiO ${ }_{2}$ presented a higher contact angle value, indicating that higher hydrophobic surface is able to provide greater protection to the carbon steel substrate. ${ }^{72,74}$ This hydrophobic surface has recently attracted extensive interest in both fundamental research and potential applications due to its unique water repellency, self-cleaning, anti-corrosion, and anti-icing properties. It is desirable to seek and utilize the enhanced functional properties of this nanocomposite coating in industry.

\subsection{Chemical conversion coatings}

Chemical conversion coating, which is adherent, insoluble, crystalline or amorphous and typically used to provide corrosion protection and a good paint-base to an underlying metal, on a metallic substrate as a superficial layer can be produced via chemical and electrochemical interactions. ${ }^{7,23,24}$ There exist numerous different conversion coatings, including chromate, ${ }^{76}$ phosphate, ${ }^{77}$ permanganate ${ }^{78}$ molybdate, ${ }^{79}$ and cerium-based
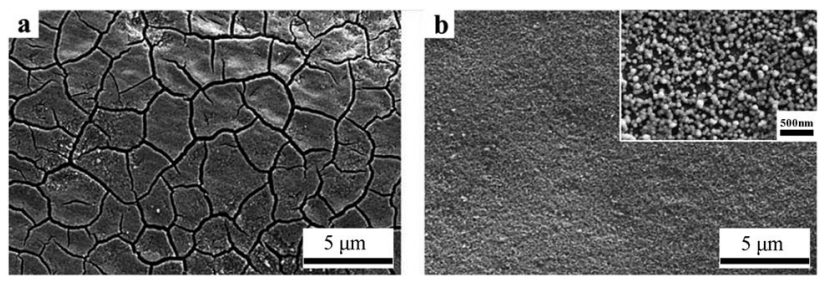

Fig. 3 SEM images of (a) $\mathrm{MCC}$ and (b) $\mathrm{MCC}-\mathrm{SiO}_{2}$ composite coatings on an AZ31 magnesium alloy. (Reproduced from ref. 84, Copyright 2013, with permission from The Electrochemical Society.) coatings, ${ }^{\mathbf{8 0}}$ according to the essential constituents of the coating. This section mainly focuses on the phosphate and molybdate conversion coatings with special emphasis on the application of inorganic nanoparticles.

2.4.1 Molybdate chemical conversion (MCC) coatings. Molybdenum itself is well known as a corrosion inhibitor when present in electrolytes as $\mathrm{Mo}(\mathrm{vI})$ or as an alloy element in steel. MCC can produce a coating of insoluble molybdate, which has been applied on $\mathrm{Mg}, \mathrm{Zn}, \mathrm{Al}$, and steel to improve their corrosion resistance. ${ }^{79,81-83}$ However, the major drawback of MCC coatings is the presence of pores and cracks, which lead to serious deterioration of this coating. Typically, an MCC coating presented a network feature, and there were many microcracks on the coating's surface (Fig. 3a), whereas there were few networklike cracks on the surface of the $\mathrm{MCC}-\mathrm{SiO}_{2}$ composite coating (Fig. 3b). It is evident that the nano- $\mathrm{SiO}_{2}$ particles are uniformly distributed in the MCC coating, as observed in the inset of Fig. 3b. The presence of nano- $\mathrm{SiO}_{2}$ acts as inert physical barriers to the initiation and development of defect corrosion of the coating, which prevent the electrolyte from penetrating into the substrate, thus improving the corrosion resistance of the resulting $\mathrm{MCC}-\mathrm{SiO}_{2}$ composite coating. ${ }^{84}$

2.4.2 Phosphate chemical conversion (PCC) coatings. PCC can be defined as a surface treatment of metals to provide an electrically non-conducting coating of insoluble phosphate..$^{7,85}$ Over the last few decades, PCC coatings have played a significant role in the automobile, process, and appliance industries owing to their low-cost, high-speed of operation, and good ability to afford excellent corrosion resistance, wear resistance, adhesion, and lubricative properties. ${ }^{21}$ However, PCC coatings have failed to satisfy certain harsh industrial requirements due to the presence of intrinsic micropores between phosphate crystals. In recent years, nanocomposite PCC coatings obtained by the controlled addition of inorganic nanoparticles to the bath have been studied since these composite coatings can bring about the benefits of improved anticorrosion properties

Table 4 Inorganic nanoparticles applied in the PCC coatings

\begin{tabular}{llll}
\hline Nanoparticle & Average size & Addition content & Substrate \\
\hline $\mathrm{Al}_{2} \mathrm{O}_{3}$ (ref. 86) & $100 \mathrm{~nm}$ & $2 \mathrm{~g} \mathrm{~L}^{-1}$ & AZ91D Mg alloy \\
$\mathrm{SiO}_{2}$ (ref. 87) & $30-40 \mathrm{~nm}$ & $0-4 \mathrm{~g} \mathrm{~L}^{-1}$ & $\begin{array}{l}\text { Carbon steel } \\
\mathrm{TiO}_{2} \text { (ref. 88) }\end{array}$ \\
& $30 \mathrm{~nm}$ & $0.1 \mathrm{~g} \mathrm{~L}^{-1}$ & $\begin{array}{l}\text { Hot dip } \\
\text { galvanized zinc } \\
\mathrm{ZnO}^{89}\end{array}$ \\
& $\leq 100 \mathrm{~nm}$ & $0.25-2 \mathrm{~g} \mathrm{~L}^{-1}$ & Mild steel
\end{tabular}




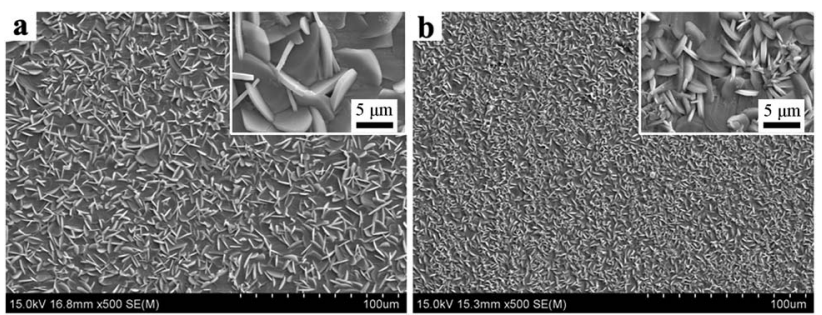

Fig. 4 FE-SEM images of (a) PCC coating and (b) $\mathrm{PCC}-\mathrm{SiO}_{2}$ composite coating on $35 \mathrm{CrMnSi}$ steel. (Reproduced from ref. 90, Copyright 2016, with permission from The Electrochemical Society.)

induced by the nanoparticles. Regarding nanocomposite PCC coatings, only a few studies on the corrosion protection of metals using this coating have been reported. The inorganic nanoparticles applied in the PCC coatings include nano- $\mathrm{Al}_{2} \mathrm{O}_{3}$, $\mathrm{SiO}_{2}, \mathrm{TiO}_{2}$, and $\mathrm{ZnO}$, as shown in Table 4 .

Similarly, the microstructure of nanocomposite PCC coatings is affected by the incorporation of nanoparticles into the coating. For instance, the PCC-SiO ${ }_{2}$ composite coating (Fig. 4b) presents a compact and fine-crystalline microstructure compared to the traditional PCC coating (Fig. 4a). ${ }^{90}$ The reason for this is as follows: nanoparticles act as nucleation agents owing to their particular surface activity and tend to be easily deposited on the metallic substrate surface. Thus, the presence of nanoparticles effectively reduces the activation energy during the formation of a new phase, which is beneficial for the formation of a PCC coating and increases the primary crystals. More primary crystals result in a denser morphology with finer crystals. ${ }^{87,91}$ Accordingly, the compact and fine-crystalline microstructure effectively facilitates the enhancement of the corrosion resistance of the PCC$\mathrm{SiO}_{2}$ composite coating. Additionally, nanoparticles, including $\mathrm{Al}_{2} \mathrm{O}_{3}, \mathrm{SiO}_{2}, \mathrm{TiO}_{2}$, and $\mathrm{ZnO}$, incorporated PCC coatings exhibit a higher coating weight, greater surface coverage, and enhanced corrosion resistance than normal PCC coatings. ${ }^{86-89}$ However, there is currently no proof for the effect of nanoparticles on the mechanical properties of chemical conversion coatings. This may be due to the developmental delay in the use of nanoparticles in the chemical conversion coatings. However, we are sure that over time, related studies will soon be reported in the future.

\section{Dispersion methods of inorganic nanoparticles}

Generally, for the production of nanocomposite coatings by the incorporation of nanoparticles into the original coating, nanoparticles are directly added into the treatment bath. It is well known that nanoparticles with a large surface area and high surface free energy tend to agglomerate in the treatment bath. In fact, the dispersion of nanoparticles in the bath plays a major role in the coating structure and performances. The agglomeration of nanoparticles bestows poor properties to the nanocomposite coatings. ${ }^{28}$ Hence, how to improve the dispersion of nanoparticles has become a crucial challenge. Attempts, such as mechanical stirring, ultrasonic vibration, and the addition of surfactants, as well as the use of a magnetic field, to achieve good dispersion of nanoparticles have been made by many researchers. A detailed discussion of these methods is as follows.

\subsection{Mechanical stirring}

Nowadays, mechanical stirring usually refers to magnetic stirring, which is the most common and direct method. For solid nanoparticles, when they are added to a solution, magnetic stirring is generally adopted to achieve preliminary dispersion through the transverse or longitudinal shear force generated by stirring. ${ }^{38,53,92}$ Among all the dispersion methods, this is the easiest method for the dispersion of nanoparticles in the treatment solution. However, the shortcoming of this method is that the reaggregation of nanoparticles occurs due to the presence of van der Waals forces once stirring is suspended., ${ }^{\mathbf{5 1 1}}$

\subsection{Ultrasonic irradiation (UI)}

Ultrasonic irradiation (UI) for the dispersion of nanoparticles has been widely employed due to the unique feature that acoustic cavitation presents with the use of UI in solution..$^{\mathbf{5 1 3}, 93,94}$ The cavitation bubbles can produce instantaneous high pressure and strong shock waves like a series of small explosions, which weaken the interactions between the nanoparticles, resulting in the effective and even dispersion of the nanoparticles, as shown in Fig. 5. ${ }^{95}$ Many studies have indicated that the implementation of UI in surface treatments involving nanoparticles can bring about numerous benefits, not only as a tool to enhance the dispersion of nanoparticles in the treatment bath, but also to improve the incorporation of dispersed nanoparticles into a surface coating. Nanocomposite coatings under UI show a further enhancement in the corrosion resistance and mechanical properties such as hardness and wear resistance. In our previous study, it was demonstrated that UI is beneficial for the uniform distribution of $\mathrm{Al}_{2} \mathrm{O}_{3}$ particles in the PCC coatings. ${ }^{92} \mathrm{Qu}$ et al. ${ }^{96}$ also reported that the introduction of UI resulted in diminished agglomeration of the $\mathrm{Al}_{2} \mathrm{O}_{3}$ nanowhiskers incorporated in plated coatings and led to a sharp increase in the microhardness of nanocomposite coatings. Similarly, Habib et al. ${ }^{28}$ dispersed diamond nanoparticles in the electroless bath by UI to not only overcome nanoparticle agglomeration but also to promote the diamond incorporation into the coating. From the abovementioned discussion, it can be clearly seen that UI can be extremely

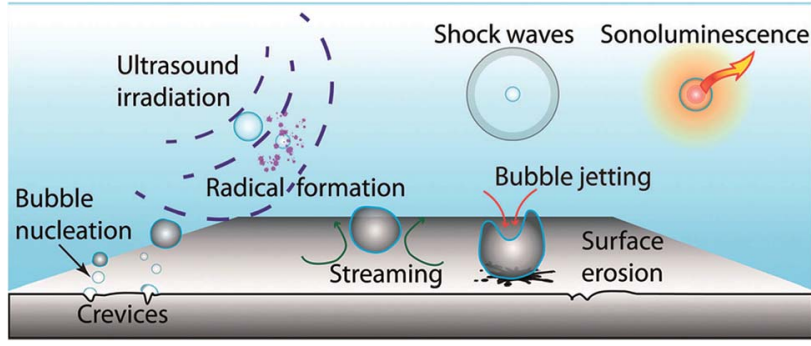

Fig. 5 Schematic for the main effects of cavitation induced by UI. (Reproduced from ref. 95, Copyright 2012, with permission from the Royal Society of Chemistry.) 
efficient and is applicable to a broad range of resulting nanocomposite coatings.

\subsection{Surfactant addition}

The dispersion of nanoparticles is a balance process of dispersion and flocculation. To some extent, physical stirring can achieve the dispersion of nanoparticles in liquid media, but reaggregation will happen due to the presence of van der Waals forces between the nanoparticles once physical stirring is suspended.,55,52 Surfactants are often utilized in suspension systems, where they are responsible for the uniformity and stability of the suspension. The theory is that surfactants can change the surface nature of the nanoparticles and thus alter the interaction between the nanoparticles and nanoparticles or liquid medium via a chemical method through adsorption on the nanoparticle surface, which not only improves the strong repulsive force between the nanoparticles but also effectively restrains reaggregation. ${ }^{\mathbf{1 1 4 6}}$ Recently, surfactants have been widely used in electroplating and electroless plating. For instance, Chen et $a l .{ }^{52}$ reported that the addition of the surfactant hexadecylpyridinium bromide in the plating bath improved the amount of co-deposited $\mathrm{Al}_{2} \mathrm{O}_{3}$ particles, reduced the agglomeration of particles, and achieved a more uniform distribution of $\mathrm{Al}_{2} \mathrm{O}_{3}$ particles in the Ni matrix. Moreover, $\mathrm{K}$. Zielińska $^{46}$ investigated the influence of cationic, anionic, and nonionic surfactants on the electroless process and indicated that the surfactant type has a significant effect on this process. However, the use of surfactants in silane and chemical conversion coatings is relatively rare, which is possibly due to the disturbance caused by surfactants during the formation of the coating.

\subsection{Magnetic field}

In a sense, it is a novel method to use a magnetic field to directly achieve a good dispersion of nanoparticles. At present, there is only one report stating that the presence of a magnetic field reduces the tendency for $\mathrm{Al}_{2} \mathrm{O}_{3}$ nanoparticle sedimentation in the PCC bath and favors the embedding of $\mathrm{Al}_{2} \mathrm{O}_{3}$ nanoparticles in the coating, as shown in Fig. 6. Results showed that the dispersibility of the nano- $\mathrm{Al}_{2} \mathrm{O}_{3}$ particles in the treatment bath greatly differed in the presence and absence of a magnetic field, where the nano- $\mathrm{Al}_{2} \mathrm{O}_{3}$ was welldispersed in the former but most of the nano- $\mathrm{Al}_{2} \mathrm{O}_{3}$ agglomerated and sedimented in the latter. Further, nano- $\mathrm{Al}_{2} \mathrm{O}_{3}$ was observed in the conversion coating in the presence of a magnetic field (Fig. 6a). However, no nano- $\mathrm{Al}_{2} \mathrm{O}_{3}$ was detected in the absence of a magnetic field (Fig. 6b). This effect is attributed to the fact that there were scarcely any nano- $\mathrm{Al}_{2} \mathrm{O}_{3}$ particles that reached the substrate surface during the formation of the coating because of strong sedimentation. ${ }^{86}$ Moreover, the utility of a magnetic field as a control measure in certain chemical conversion processes has been investigated. Some researchers ${ }^{97-100}$ have reported that the application of an external magnetic field could improve the quality of chemical conversion coatings because

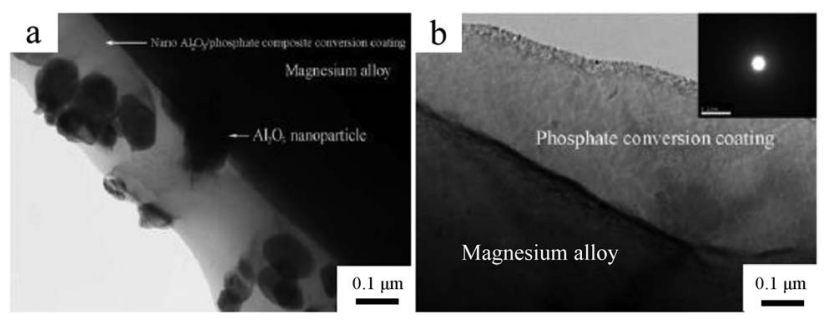

Fig. 6 TEM images of (a) $\mathrm{PCC}-\mathrm{Al}_{2} \mathrm{O}_{3}$ composite coating in the presence of a magnetic field of $0.3 \mathrm{~T}$ and (b) PCC coating in the absence of a magnetic field after $8 \mathrm{~min}$ of immersion in a treatment bath containing $2 \mathrm{~g} \mathrm{~L}^{-1} \mathrm{Al}_{2} \mathrm{O}_{3}$ nanoparticles. (Reproduced from ref. 86, Copyright 2013, with permission from The Electrochemical Society.)

there is strong, localized convection arising from the micro magnetohydrodynamic effect. Briefly, this method can not only improve the dispersion of nanoparticles, but also benefit the quality of matrix coatings and is therefore considered to be a promising approach.

\subsection{Sol solution addition}

The abovementioned methods, including mechanical stirring, ultrasonic vibration, and surfactants addition, are often used to help maintain the separation of nanoparticles in the solution. To some extent, these methods may reduce the tendency of nanoparticle agglomeration, but are unable to achieve good dispersion drastically due to the large surface area and high surface energy of nanoparticles themselves. However, Chen et al. ${ }^{44}$ developed a novel technique of sol-gel enhanced electroless plating to prepare highly dispersive nano- $\mathrm{TiO}_{2}$ reinforced coating for improving the microhardness and wear resistance. A transparent sol solution containing desirable $\mathrm{TiO}_{2}$ was directly added to the electroless bath at a controlled speed. Subsequently, nano- $\mathrm{TiO}_{2}$ was formed in situ and co-deposited with metals to form a Ni-P$\mathrm{TiO}_{2}$ composite coating. Similarly, the sol-enhanced $\mathrm{Ni}-\mathrm{TiO}_{2}$ composite electroplating coating possessed a smooth surface and compact microstructure and showed higher mechanical properties compared with the traditional composite coatings, which resulted from the highly dispersed $\mathrm{TiO}_{2}$ nanoparticles. Moreover, the in situ formation of fine $\mathrm{TiO}_{2}$ nanoparticles changed the electrochemical behavior and polarization mechanism, avoiding the loose and dendritic surface structure at higher current deposition. ${ }^{56,69}$ In our laboratory, the $\mathrm{PCC}-\mathrm{SiO}_{2}$ composite coating prepared in a PCC bath with the addition of $100 \mathrm{~mL} \mathrm{~L}^{-1} \mathrm{SiO}_{2}$-sol possessed a compact, uniform, and fine-crystal microstructure, as well as enhanced corrosion resistance, showing that the introduction of $\mathrm{SiO}_{2}$-sol into the PCC bath drastically avoids the agglomeration of nano- $\mathrm{SiO}_{2}$ and causes the coating to have smooth crystal surfaces. ${ }^{\mathbf{9 0}}$ The alternative technique of introducing nanoparticles into the bath can effectively avoid the agglomeration of nanoparticles and thus significantly improve the dispersion strengthening effect. ${ }^{55,101}$ It is suggested that this novel processing concept can be exploited in many other nanocomposite coating systems and thereby can broaden the application prospect of nanoparticles in surface coatings. 


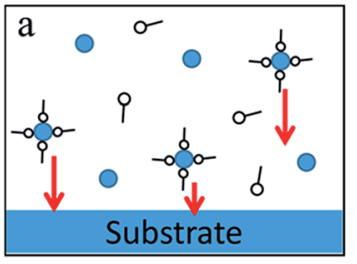

Nanoparticle

o- Metal ion
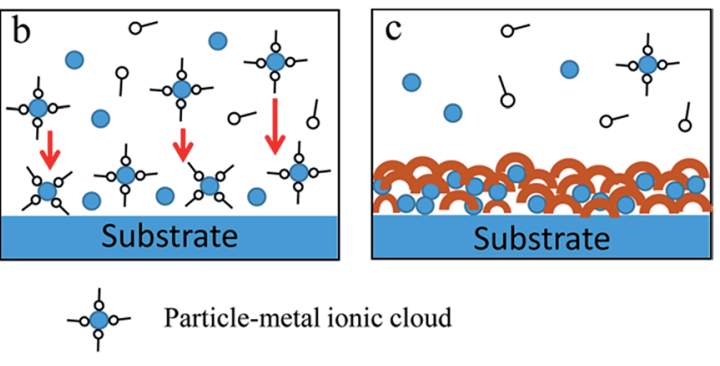

Deposited metal

Fig. 7 Schematic for the formation process of nanocomposite coatings prepared in baths with the controlled addition of nanoparticles.

\section{Mechanism}

Most of the studies reported in the literature have mainly focused on the production and characterization, including those of the microstructure, corrosion resistance, and mechanical properties, of nanocomposite coatings. Other than this, it is more significant to understand how nanoparticles may affect the formation of nanocomposite coatings. The mechanism of the formation of nanocomposite electrochemical coatings (including electroplating and electroless plating) has been investigated since the 1960s and three main steps have been defined as follows: (i) electrophoretic movement of positively charged particles to the cathode, (ii) adsorption of particles at the electrode surface by van der Waals forces, and (iii) mechanical inclusion of particles into the coating layer. ${ }^{11,67,69}$ In fact, nanoparticles are inert and cannot participate in chemical reactions during the coating formation, whereas they can affect the formation process. Generally, nanoparticles with high surface activity and high surface energy can be easily absorbed by some other objects and thus affect the reaction process. This effect on the formation of different coatings has different reaction mechanisms. For this, a schematic for the formation processes of nanocomposite coatings prepared in the treatment baths with controlled addition of nanoparticles is preliminary presented, as seen in Fig. 7. Some of the possible reaction processes of the nanocomposite coatings are depicted as follows.

\subsection{Suspension in the treatment bath}

With the immersion of nanoparticles into the treatment bath, they are dispersed in the bath through some effective dispersion methods to form a suspension system. Generally, the nanoparticles in the chemical conversion bath are relatively stable before the anions and cations in the bath reach saturation at the initial stage. ${ }^{7,24}$ However, the nanoparticles-adsorbed metal ionic cloud (referred to as the particle-metal ionic cloud) is formed as soon as the particles are introduced into the plating bath containing an abundance of metal ions, ${ }^{67,69}$ as shown in Fig. 7a.

\subsection{Adsorption on the substrate surface}

In Fig. 7b, the nanoparticles themselves with both high surface activity and large specific area are immediately physically adsorbed on the freshly deposited surface in the chemical conversion treatment bath due to the dynamic field ${ }^{\mathbf{1 0 2}}$ by the dispersion methods and Brownian motion ${ }^{5}$ of the nanoparticles in the bath, which can provide more nucleation sites for the primary deposition of insoluble salts and effectively reduce the activation energy during the formation of a new phase. On the other hand, the particle-metal ionic clouds in the plating bath are easily adsorbed on the underlying substrate during electrochemical treatments. According to reports, ${ }^{\mathbf{1 1}, 69}$ these particlemetal ionic clouds are transported to the hydrodynamic boundary layer under the action of forced convection, migrated across the layer, and then conveyed by diffusion to the cathode.

\subsection{Formation of nanocomposite coatings}

Regarding chemical conversion coatings, when anions and metal cations in the bath reach saturation, deposition or crystallization of insoluble salts with nanoparticles as core is achieved, and then the grains quickly grow to form bigger crystals. Finally, many crystals increasingly pack, and finally, a complete and dense coating on the surface is formed. ${ }^{7,24,87}$ As for electrochemical coatings, after the clouds are entirely or partly reduced, the particles are irreversibly deposited and incorporated into the metal matrix as the metal ions are discharged with reduction reactions, ${ }^{11,69}$ as shown in Fig. 7c.

Note that an excess amount of nanoparticles in the treatment bath will have an adverse effect on the formation of the nanocomposite coating because excessive nanoparticles may seal the substrate surface by agglomeration, thus restraining the initial reactions in the formation of the coating.

\section{Conclusions}

The introduction of inorganic nanoparticles into the surface treatments, such as electroless plating, electroplating, silane and chemical conversion coatings, has been reviewed. The discussed inorganic nanoparticles, including $\mathrm{TiO}_{2}, \mathrm{SiO}_{2}, \mathrm{Al}_{2} \mathrm{O}_{3}, \mathrm{ZrO}_{2}, \mathrm{SiC}$, $\mathrm{ZnO}, \mathrm{CeO}_{2}, \mathrm{MoS}_{2}$, and diamond and graphite nanoparticles, not only improve the corrosion resistance and mechanical properties, but also enhance the functional properties, such as photocathode protection and hydrophobicity, of surface coatings. Moreover, this review summarizes the dispersion methods of nanoparticles, including mechanical stirring, ultrasonic vibration, surfactant addition, magnetic field, as well as sol 
solution addition, which play a major role in the coating structure and performance. It is concluded that these modifications for surface coatings will be increasingly welcomed considering the indubitable role of surface coatings in the automotive and aerospace fields. However, it must be pointed out that the content of nanoparticles in the treatment bath is extremely strict and the optimal content range is determined by sufficient repeated experiments in practice. It is desirable to make full use of inorganic nanoparticles with optimal contents and proper dispersion methods in surface treatments to meet the expanding industrial requirements.

\section{Acknowledgements}

This work was supported by Shandong Provincial Natural Science Foundation of China (ZR2013EMM013), Jiangsu Province Science Foundation for Youths (BK20140412) and Science and Technology Development Program of Shandong Province, China (2014GGX102031), and Independent Innovation Foundation of Shandong University of China (2015JC018).

\section{References}

1 F. Zhang, M. Reich, O. Kessler and E. Burkel, Mater. Today, 2013, 16, 192-197.

2 L. Winkless, Mater. Today, 2015, 18, 245.

3 F. Presuel-Moreno, M. A. Jakab, N. Tailleart, M. Goldman and J. R. Scully, Mater. Today, 2008, 11, 14-23.

4 C. Stromberg, P. Thissen, I. Klueppel, N. Fink and G. Grundmeier, Electrochim. Acta, 2006, 52, 804-815.

5 I. Tudela, Y. Zhang, M. Pal, I. Kerr and A. J. Cobley, Surf. Coat. Technol., 2014, 259, 363-373.

6 J. Sudagar, J. Lian and W. Sha, J. Alloys Compd., 2013, 571, 183-204.

7 T. S. N. S. Narayanan, Rev. Adv. Mater. Sci., 2005, 9, 130-177. 8 O. Kammona, K. Kotti, C. Kiparissides, J. P. Celis and J. Fransaer, Electrochim. Acta, 2009, 54, 2450-2457.

9 S.-L. Kuo, Y.-C. Chen, M.-D. Ger and W.-H. Hwu, Mater. Chem. Phys., 2004, 86, 5-10.

10 J. Novakovic and P. Vassiliou, Electrochim. Acta, 2009, 54, 2499-2503.

11 M.-D. Ger and B. J. Hwang, Mater. Chem. Phys., 2002, 76, 3845.

12 T. Liu, S.-W. Yao, L.-S. Wang, G.-J. Yang, C.-X. Li and C.-J. Li, J. Therm. Spray Technol., 2016, 25, 213-221.

13 X. C. Zhao, G. Y. Xiao, X. Zhang, H. Y. Wang and Y. P. Lu, J. Phys. Chem. C, 2014, 118, 1910-1918.

14 R.-C. Zeng, F. Zhang, Z.-D. Lan, H.-Z. Cui and E.-H. Han, Corros. Sci., 2014, 88, 452-459.

15 K. L. Choy, Prog. Mater. Sci., 2003, 48, 57-170.

16 A. Aubert, J. Danroc, A. Gaucher and J. P. Terrat, Thin Solid Films, 1985, 126, 61-67.

17 C. Blawert, A. Weisheit, B. L. Mordike and R. M. Knoop, Surf. Coat. Technol., 1996, 85, 15-27.

18 C. Tassin, F. Laroudie, M. Pons and L. Lelait, Surf. Coat. Technol., 1996, 80, 207-210.
19 Y. González-García, S. González and R. M. Souto, Corros. Sci., 2007, 49, 3514-3526.

20 M. F. Montemor, R. Pinto and M. G. S. Ferreira, Electrochim. Acta, 2009, 54, 5179-5189.

21 N. V. Phuong, K. Lee, D. Chang, M. Kim, S. Lee and S. Moon, Met. Mater. Int., 2013, 19, 273-281.

22 P. Sahoo and S. K. Das, Mater. Des., 2011, 32, 1760-1775.

23 J. E. Gray and B. Luan, J. Alloys Compd., 2002, 336, 88-113.

24 B. Liu, X. Zhang, G.-y. Xiao and Y.-p. Lu, Mater. Sci. Eng., C, 2015, 47, 97-104.

25 F. Hou, W. Wang and H. Guo, Appl. Surf. Sci., 2006, 252, 3812-3817.

26 L. Liu, J.-M. Hu, J.-Q. Zhang and C.-N. Cao, Electrochim. Acta, 2006, 52, 538-545.

27 P. C. G. Fink and J. D. Prince, Trans. Am. Electrochem. Soc., 1928, 54, 315-321.

28 H. Ashassi-Sorkhabi and M. Es'haghi, Corros. Sci., 2013, 77, 185-193.

29 S. Haag, M. Burgard and B. Ernst, Surf. Coat. Technol., 2006, 201, 2166-2173.

30 H. Zhao, Z. Huang and J. Cui, Microelectron. Eng., 2008, 85, 253-258.

31 T. Osaka, Y. Okinaka, J. Sasano and M. Kato, Sci. Technol. Adv. Mater., 2006, 7, 425-437.

32 B. Huang, W. Gan, G. Guo, Y. Li, T. Lin and X. Liu, Ceram. Int., 2014, 40, 393-397.

33 M. Kitiwan and D. Atong, J. Mater. Sci. Technol., 2010, 26, 1148-1152.

34 S. L. Cheng, T. L. Hsu, T. Lee, S. W. Lee, J. C. Hu and L. T. Chen, Appl. Surf. Sci., 2013, 264, 732-736.

35 B. Panja and P. Sahoo, Procedia Technol., 2014, 14, 173-180.

36 B. Panja and P. Sahoo, Procedia Eng., 2014, 97, 47-55.

37 Z. Li, J. Wang, J. Lu and J. Meng, Appl. Surf. Sci., 2013, 264, 516-521.

38 J. Novakovic, P. Vassiliou, K. Samara and T. Argyropoulos, Surf. Coat. Technol., 2006, 201, 895-901.

39 S. Sadreddini and A. Afshar, Appl. Surf. Sci., 2014, 303, 125130.

40 S. Sadreddini, Z. Salehi and H. Rassaie, Appl. Surf. Sci., 2015, 324, 393-398.

41 T. Rabizadeh and S. R. Allahkaram, Mater. Des., 2011, 32, 133-138.

42 M. Islam, M. R. Azhar, N. Fredj, T. D. Burleigh, O. R. Oloyede, A. A. Almajid and S. Ismat Shah, Surf. Coat. Technol., 2015, 261, 141-148.

43 D. Dong, X. H. Chen, W. T. Xiao, G. B. Yang and P. Y. Zhang, Appl. Surf. Sci., 2009, 255, 7051-7055.

44 W. Chen, W. Gao and Y. He, Surf. Coat. Technol., 2010, 204, 2493-2498.

45 A. Sharma and A. K. Singh, J. Mater. Eng. Perform., 2012, 22, 176-183.

46 K. Zielińska, A. Stankiewicz and I. Szczygieł, J. Colloid Interface Sci., 2012, 377, 362-367.

47 A. Farzaneh, M. Mohammadi, M. Ehteshamzadeh and F. Mohammadi, Appl. Surf. Sci., 2013, 276, 697-704.

48 H. Jin, S. Jiang and L. Zhang, J. Rare Earths, 2009, 27, 109113. 
49 C.-K. Lee, J. Power Sources, 2012, 220, 130-137.

50 X. G. Hu, W. J. Cai, Y. F. Xu, J. C. Wan and X. J. Sun, Surf. Eng., 2009, 25, 361-366.

51 M. Alishahi, S. M. Monirvaghefi, A. Saatchi and S. M. Hosseini, Appl. Surf. Sci., 2012, 258, 2439-2446.

52 L. Chen, L. Wang, Z. Zeng and J. Zhang, Mater. Sci. Eng., A, 2006, 434, 319-325.

53 N. S. Qu, D. Zhu and K. C. Chan, Scr. Mater., 2006, 54, 14211425.

54 M. A. Juneghani, M. Farzam and H. Zohdirad, Trans. Nonferrous Met. Soc. China, 2013, 23, 1993-2001.

55 W. Chen, W. Gao and Y. He, J. Sol-Gel Sci. Technol., 2010, 55, 187-190.

56 W. Chen and W. Gao, Electrochim. Acta, 2010, 55, 68656871.

57 W. Wang, F.-Y. Hou, H. Wang and H.-T. Guo, Scr. Mater., 2005, 53, 613-618.

58 M. R. Vaezi, S. K. Sadrnezhaad and L. Nikzad, Colloids Surf., A, 2008, 315, 176-182.

59 Y.-J. Xue, H.-B. Liu, M.-M. Lan, J.-S. Li and H. Li, Surf. Coat. Technol., 2010, 204, 3539-3545.

60 E. García-Lecina, I. García-Urrutia, J. A. Díez, J. Morgiel and P. Indyka, Surf. Coat. Technol., 2012, 206, 2998-3005.

61 H. Gül, F. Kılıç, S. Aslan, A. Alp and H. Akbulut, Wear, 2009, 267, 976-990.

62 D. Dietrich, I. Scharf, D. Nickel, L. Shi, T. Grund and T. Lampke, J. Solid State Electrochem., 2011, 15, 1041-1048.

63 E. Beltowska-Lehman, P. Indyka, A. Bigos, M. J. Szczerba and M. Kot, Mater. Des., 2015, 80, 1-11.

64 R. Sen, S. Bhattacharya, S. Das and K. Das, J. Alloys Compd., 2010, 489, 650-658.

65 G. Parida, D. Chaira, M. Chopkar and A. Basu, Surf. Coat. Technol., 2011, 205, 4871-4879.

66 B. Łosiewicz, Mater. Chem. Phys., 2011, 128, 442-448.

67 W.-w. Chen and W. Gao, Prog. Nat. Sci.: Mater. Int., 2011, 21, 355-362.

68 W. Chen and W. Gao, Composites, Part A, 2011, 42, 16271634.

69 W. Chen, Y. He and W. Gao, J. Electrochem. Soc., 2010, 157, E122.

70 V. Palanivel, D. Zhu and W. J. van Ooij, Prog. Org. Coat., 2003, 47, 384-392.

71 L. Liu, J.-M. Hu, W.-H. Leng, J.-Q. Zhang and C.-N. Cao, Scr. Mater., 2007, 57, 549-552.

72 P. H. Suegama, H. G. de Melo, A. A. C. Recco, A. P. Tschiptschin and I. V. Aoki, Surf. Coat. Technol., 2008, 202, 2850-2858.

73 M. Li, Y.-Q. Yang, L. Liu, J.-M. Hu and J.-Q. Zhang, Electrochim. Acta, 2010, 55, 3008-3014.

74 P. H. Suegama, A. A. C. Recco, A. P. Tschiptschin and I. V. Aoki, Prog. Org. Coat., 2007, 60, 90-98.

75 M. F. Montemor, W. Trabelsi, S. V. Lamaka, K. A. Yasakau, M. L. Zheludkevich, A. C. Bastos and M. G. S. Ferreira, Electrochim. Acta, 2008, 53, 5913-5922.
76 A. A. O. Magalhães, I. C. P. Margarit and O. R. Mattos, Electrochim. Acta, 1999, 44, 4281-4287.

77 W. Zhou, D. Shan, E.-H. Han and W. Ke, Corros. Sci., 2008, 50, 329-337.

78 F. Zucchi, A. Frignani, V. Grassi, G. Trabanelli and C. Monticelli, Corros. Sci., 2007, 49, 4542-4552.

79 A. A. O. Magalhães, I. C. P. Margarit and O. R. Mattos, J. Electroanal. Chem., 2004, 572, 433-440.

80 K. Brunelli, M. Dabalà, I. Calliari and M. Magrini, Corros. Sci., 2005, 47, 989-1000.

81 D. E. Walker and G. D. Wilcox, Trans. IMF, 2008, 86, 251259.

82 A. S. Hamdy, A. M. Beccaria and P. Traverso, J. Appl. Electrochem., 2005, 35, 467-472.

83 Z. Yong, J. Zhu, C. Qiu and Y. Liu, Appl. Surf. Sci., 2008, 255, 1672-1680.

84 Y. W. Yao, Y. Zhou, C. M. Zhao, Y. X. Han and C. X. Zhao, J. Electrochem. Soc., 2013, 160, C185-C188.

85 H.-Y. Su and C.-S. Lin, Corros. Sci., 2014, 83, 137-146.

86 M. Zhao, J. Li, G. He, H. Xie and Y. Fu, J. Electrochem. Soc., 2013, 160, C553-C559.

87 M. Sheng, Y. Wang, Q. Zhong, H. Wu, Q. Zhou and H. Lin, Surf. Coat. Technol., 2011, 205, 3455-3460.

88 S. M. A. Shibli and F. Chacko, Appl. Surf. Sci., 2011, 257, 3111-3117.

89 M. Tamilselvi, P. Kamaraj, M. Arthanareeswari and S. Devikala, Appl. Surf. Sci., 2015, 327, 218-225.

90 C.-c. Jiang, R.-f. Zhu, G.-y. Xiao, Y.-z. Zheng, L.-l. Wang and Y.-p. Lu, J. Electrochem. Soc., 2016, 163, C571-C575.

91 M. Tamilselvi, P. Kamaraj, M. Arthanareeswari, S. Devikala and J. A. Selvi, Appl. Surf. Sci., 2015, 332, 12-21.

92 C.-c. Jiang, G.-y. Xiao, X.-c. Zhao, X. Zhang, R.-f. Zhu and Y.-p. Lu, ECS Electrochem. Lett., 2015, 4, C23-C25.

93 B. Díaz, L. Freire, M. Mojío and X. R. Nóvoa, J. Electroanal. Chem., 2015, 737, 174-183.

94 M. Sheng, C. Wang, Q. Zhong, Y. Wei and Y. Wang, Ultrason. Sonochem., 2010, 17, 21-25.

95 D. Fernandez Rivas, P. Cintas and H. J. Gardeniers, Chem. Commun., 2012, 48, 10935-10947.

96 N. S. Qu, K. C. Chan and D. Zhu, Scr. Mater., 2004, 50, 11311134.

97 M. Zhao, L. Zhu and G. P. He, Appl. Surf. Sci., 2011, 189-193, 805-809.

98 M. Zhao, J. Li, G. He, H. Xie and Y. Fu, Appl. Surf. Sci., 2013, 282, 499-505.

99 A. Yanovska, V. Kuznetsov, A. Stanislavov, S. Danilchenko and L. Sukhodub, Appl. Surf. Sci., 2012, 258, 8577-8584.

100 G. Bikulčius, V. Burokas, A. Martušiene and E. Matulionis, Surf. Coat. Technol., 2003, 172, 139-143.

101 X. Wu, J. Mao, Z. Zhang and Y. Che, Surf. Coat. Technol., 2015, 270, 170-174.

102 R. Dastjerdi and M. Montazer, Colloids Surf., B, 2010, 79, 518. 